\title{
The Association of Toll-Like Receptor 4 Polymorphism with Hepatitis C Virus Infection in Saudi Arabian Patients
}

\author{
Ahmed A. Al-Qahtani, ${ }^{1,2,3}$ Mashael R. Al-Anazi, ${ }^{1}$ Fahad Al-Zoghaibi, ${ }^{4}$ \\ Ayman A. Abdo, ${ }^{3,5}$ Faisal M. Sanai, ${ }^{3,6}$ Mohammed Q. Khan, ${ }^{7}$ Ali Albenmousa, ${ }^{8}$ \\ Hamad I. Al-Ashgar, ${ }^{7}$ and Mohammed N. Al-Ahdal ${ }^{1,2,9}$ \\ ${ }^{1}$ Department of Infection and Immunity, Research Center, King Faisal Specialist Hospital \& Research Center, \\ Riyadh 11211, Saudi Arabia \\ ${ }^{2}$ Department of Microbiology and Immunology, Alfaisal University School of Medicine, Riyadh, Saudi Arabia \\ ${ }^{3}$ Liver Disease Research Center, King Saud University, Riyadh, Saudi Arabia \\ ${ }^{4}$ Molecular BioMedicine Program, Research Center, King Faisal Specialist Hospital \& Research Center, Riyadh, Saudi Arabia \\ ${ }^{5}$ Department of Medicine, College of Medicine, King Saud University, Riyadh, Saudi Arabia \\ ${ }^{6}$ Division of Gastroenterology, Department of Medicine, King Abdulaziz Medical City, Jeddah, Saudi Arabia \\ ${ }^{7}$ Department of Medicine, King Faisal Specialist Hospital \& Research Center, Riyadh, Saudi Arabia \\ ${ }^{8}$ Department of Gastroenterology \& Hepatology, Prince Sultan Military Medical City, Riyadh, Saudi Arabia \\ ${ }^{9}$ Department of Pathology and Laboratory Medicine, King Faisal Specialist Hospital and Research Center, Riyadh, Saudi Arabia
}

Correspondence should be addressed to Ahmed A. Al-Qahtani; aqahtani@kfshrc.edu.sa

Received 1 June 2014; Accepted 9 July 2014; Published 10 August 2014

Academic Editor: Masayuki Kurosaki

Copyright ( 2014 Ahmed A. Al-Qahtani et al. This is an open access article distributed under the Creative Commons Attribution License, which permits unrestricted use, distribution, and reproduction in any medium, provided the original work is properly cited.

Hepatitis $\mathrm{C}$ virus (HCV) is a single stranded RNA virus. It affects millions of people worldwide and is considered as a leading cause of liver diseases including cirrhosis and hepatocellular carcinoma. A recent study reported that TLR4 gene polymorphisms are good prognostic predictors and are associated with protection from liver fibrosis among Caucasians. This study aims to investigate the implication of genetic polymorphisms of TLR4 gene on the HCV infection in Saudi Arabian patients. Two SNPs in the TLR4 gene, rs4986790 (A/G) and rs4986791 (C/T), were genotyped in $450 \mathrm{HCV}$ patients and 600 uninfected controls. The association analysis confirmed that both SNPs showed a significant difference in their distribution between HCV-infected patients and uninfected control subjects $(P<0.0001$; OR $=0.404,95 \% \mathrm{CI}=0.281-0.581)$ and $(P<0.0001$; $\mathrm{OR}=0.298,95 \% \mathrm{CI}=0.201-0.443)$, respectively. More importantly, haplotype analysis revealed that four haplotypes, AC, GT, GC, and AT (rs4986790, rs4986791), were significantly associated with HCV infection when compared with control subjects. One haplotype AC was more prominently found when chronic HCV-infected patients were compared with cirrhosis/HCC patients (frequency $=94.7 \%$ and $P=0.04$ ). Both TLR4 SNPs under investigation were found to be significantly implicated with HCV-infection among Saudi Arabian population.

\section{Introduction}

Hepatitis $\mathrm{C}$ virus (HCV) is a major global health problem, affecting more than 180 million people worldwide [1]. HCV genome is a single strand-RNA of a positive polarity and has a length of $\sim 10 \mathrm{~kb}$ encoding a polyprotein of 3000 amino acids (aa) and flanked by $5^{\prime}$ and $3^{\prime}$ end untranslated region (UTR).
Viral structural proteins (C, E1, and E2) are encoded by genes located at the $\mathrm{N}$-terminal segment of the genome, while nonstructural (NS) proteins, encoded by genes located at the $\mathrm{C}$-terminus of the open reading frame (ORF), include $\mathrm{p} 7$, NS2, NS3, NS4B, NS5A, and NS5B [2]. Based on phylogenetic studies, HCV was classified into six genotypes. However, it was reported that genotypes 1 and 4 are more resistant to 
the standard HCV treatment of pegylated interferon/ribavirin therapy [3].

Chronic HCV infection leads to variable degrees of hepatic inflammation with an increased risk of progression to cirrhosis and hepatocellular carcinoma (HCC) [4]. It is known that the host genetic background can influence the outcome of HCV infection. Several polymorphisms were found to be associated with HCV infection with many studies reporting the role of alleles, DQB1 ${ }^{*} 0301$ and DRB1 ${ }^{*} 1101$ in HCV clearance [5], while, other studies have found that variations in IL28B gene region to be significantly associated with spontaneous viral clearance, response to treatment with pegylated interferon (PEG-IFN)-based therapy $[6,7]$ and with the progression of the disease $[8,9]$. HCV infection was implicated in a robust innate immune response including induction of interferon stimulated genes (ISGs) [10, 11]. The innate immune response is the first line of pathogenic defense which can be mediated by pathogen-derived signals such as lipopolysaccharide (LPS) from gram negative bacteria or viral DNA which are recognized by toll-like receptors (TLRs). TLRs belong to a highly conserved family of pattern recognition receptors that are capable of binding to pathogen associated molecular patterns (PAMPs), which upon activation lead to expression of inflammatory cytokines [12]. In a study conducted by Düesberg et al. [13], synthetic lipopeptide complexes of the HCV core protein were found to stimulate the innate immune response via TLR2 and TLR4. This was confirmed by other studies showing that HCV proteins, such as core and NS3, can activate human monocytes and macrophages via TLR2 $[14,15]$. Other studies have also shown that HCV structural and nonstructural proteins interfere with the innate immunity signaling pathway through the interaction of ISGs [16-18].

TLR4, one of the most important and well-studied TLRs, is located on chromosome 9q32-33. TLR4 is known to recognize bacterial LPS but this receptor has also been found to recognize fusion protein from the respiratory syncytial virus (RSV) and the envelope protein of mouse mammary tumor virus (MMTV) [19,20]. Reports have also shown that TLR 4 can be stimulated by HCV nonstructural protein NS5A and thereby results in the secretion of IFNs and IL6 from hepatocyte and B cells [21]. The activation of TLR2 and TLR4 signaling in hepatocyte leads to upregulation of proinflammatory cytokines and chemokines and recruitment of inflammatory cells to the liver [22].

Recently, TLR4 gene polymorphism Thr399Ile (rs4986791) was identified to be a good prognostic predic-tor for the development of cirrhosis in HCV infected patients $[23,24]$. Also, it was shown that TLR4 SNPs, rs4986790 (D299G) and rs4986791 (T399I), are associated with protection from liver fibrosis, possibly through conformational changes of the protein, thereby affecting its interaction with other proteins [25].

In this study, we explored the association of the two cosegregating TLR4 single nucleotide polymorphisms (SNPs), rs4986790 and rs4986791, with HCV infection and the progression of the disease to liver cirrhosis and HCC in HCV infected Saudi patient.

\section{Methods}

2.1. Study Subjects. In this study, a total of 1050 subjects of Saudi origin, were recruited from three centers in Riyadh, Saudi Arabia, (King Faisal Specialist Hospital and Research Center, Riyadh Military Hospital and King Khalid University Hospital) between August 2007 and August 2010. These subjects include $450 \mathrm{HCV}$-infected subjects who were categorized as chronic HCV carriers (CHC), HCV-infected patients with liver cirrhosis (Cirr) who do not exhibit any clinical evidence of HCC, and patients who have progressed to HCC. Also, 600 randomly selected uninfected healthy controls that were serologically and PCR negative for HCV. The study protocol was approved by the institutional review boards of the three centers and conformed to the ethical guidelines of the 1975 Helsinki Declaration. Prior to their enrollment in this study, a written informed consent was obtained from all patients and their basic demographic data were recorded.

CHC subjects were diagnosed based on persistent detection of both HCV antibody and serum HCV RNA for at least six months with no signs of liver complications. Cirr was determined based on liver biopsy or diagnosed by the presence of at least two of the following: (a) radiological evidence (ultrasonography or computed tomography), platelet count $<90,000 / \mathrm{L}$, or the presence of esophageal varices (demonstrated by endoscopy) and (b) at least two signs of liver dysfunction; Albumin level $<30 \mathrm{~g} / \mathrm{L}$, INR $\geq 1.5$ or Bilirubin level $>35 \mu \mathrm{mol} / \mathrm{L}$. The diagnosis of HCC was made using noninvasive methods such as triphasic CT and/or MRI showing arterial enhancement of a liver lesion [26]. Patients diagnosed with other infections such as HBV or HIV were excluded from this study.

\subsection{DNA Extraction and Genotyping of SNPs. Genomic DNA} was extracted from peripheral blood mononuclear cells (PBMC) using Gentra Pure Gene kit (Qiagen, Hilden, Germany) according to the manufacturer's protocol. Samples from patients and control subjects were genotyped for the two polymorphic sites using TaqMan allelic discrimination assay with the 7900 HT Fast Real Time PCR System (Applied Biosystems, Foster City, CA, USA). All reagents required for the TaqMan assay including universal master mix, amplifying primers, and probes were purchased from Applied Biosystems (Foster City, CA, USA). The assay ID for rs 4986790 is C_11722238_20 and for rs4986791 is C_11722237_20. One allelic probe was labeled with FAM dye and the other with the fluorescent VIC dye. PCR was run in the TaqMan universal master mix at a probe concentration of $20 \mathrm{x}$ in a 96-well format using $20 \mathrm{ng}$ of genomic DNA in a total reaction volume of $25 \mu \mathrm{L}$. The PCR reaction conditions were as follows: plates were heated to $50^{\circ} \mathrm{C}$ for $2 \mathrm{mins}$ and then to $95^{\circ} \mathrm{C}$ for $10 \mathrm{mins}$; followed by 40 cycles of $95^{\circ} \mathrm{C}$ for $15 \mathrm{~s}$ and $60^{\circ} \mathrm{C}$ for 1.5 mins. The fluorescence intensity of each well in the TaqMan assay plate was read and the fluorescence data files from each plate were analyzed using automated allelecalling software (SDS 2.4) (Applied Biosystems, Foster City, CA, USA). 
TABLE 1: Information of SNPs in TLR4 gene.

\begin{tabular}{lcccccc}
\hline Name & Position & ObsHET & PredHET & HWpval & MAF & Alleles \\
\hline rs4986790 & 120475302 & 0.156 & 0.147 & 0.0551 & 0.08 & A:G \\
rs4986791 & 120475602 & 0.154 & 0.144 & 0.017 & 0.078 & C:T \\
\hline
\end{tabular}

TABLE 2: Genotypic distribution of TLR4 SNPs between healthy control subjects and HCV-infected patients.

\begin{tabular}{|c|c|c|c|c|c|c|}
\hline SNPs & $\begin{array}{c}\text { Genotype/allele } \\
\text { distribution }\end{array}$ & $\begin{array}{c}\text { Healthy control } \\
\text { subjects }\end{array}$ & $\begin{array}{c}\text { HCV-infected } \\
\text { patients }\end{array}$ & OR (95\% CI.) & $\chi^{2}$ & $P$ value \\
\hline \multirow{7}{*}{ rs4986791 } & $\mathrm{CC}$ & $469(78.1 \%)$ & $418(93.0 \%)$ & 1.0000 (Ref.) & & \\
\hline & $\mathrm{CT}$ & $130(21.7 \%)$ & $32(7.0 \%)$ & $0.276(0.184-0.416)$ & 41.90 & $<0.0001$ \\
\hline & $\mathrm{TT}$ & $1(0.2 \%)$ & $0(0 \%)$ & $0.374(0.000-10.803)$ & 0.39 & 0.531 \\
\hline & $\mathrm{C}$ & $1068(89.0 \%)$ & $868(96.4 \%)$ & 1.0000 (Ref.) & & \\
\hline & $\mathbf{T}$ & $132(11.0 \%)$ & $32(3.6 \%)$ & $0.298(0.201-0.443)$ & 39.59 & $<0.0001$ \\
\hline & $\mathrm{TT}+\mathrm{CT}$ versus CC & & & $0.274(0.182-0.412)$ & 42.50 & $<0.0001$ \\
\hline & TT versus $\mathrm{CT}+\mathrm{CC}$ & & & $0.444(0.000-12.805)$ & 0.26 & 0.609 \\
\hline \multirow{7}{*}{ rs4986790 } & $\mathrm{AA}$ & $475(79.2 \%)$ & $408(90.9 \%)$ & 1.0000 (Ref.) & & \\
\hline & AG & $123(20.5 \%)$ & $41(9.1 \%)$ & $0.388(0.266-0.566)$ & 25.39 & $<0.0001$ \\
\hline & GG & $2(0.3 \%)$ & $0(0 \%)$ & $0.233(0.000-4.472)$ & 1.05 & 0.305 \\
\hline & $\mathrm{A}$ & $1073(89.4 \%)$ & $857(95.4 \%)$ & 1.0000 (Ref.) & & \\
\hline & G & $127(10.6 \%)$ & $41(4.6 \%)$ & $0.404(0.281-0.581)$ & 25.25 & $<0.0001$ \\
\hline & GG versus $A G+A A$ & & & $0.266(0.000-5.110)$ & 0.84 & 0.359 \\
\hline & $\mathrm{GG}+\mathrm{AG}$ versus $\mathrm{AA}$ & & & $0.382(0.262-0.557)$ & 26.40 & $<0.0001$ \\
\hline
\end{tabular}

Risk allele marked in bold letters.

2.3. Statistical Analysis. Allelic and genotypic frequencies were estimated by direct counting and Pearson's chi-squared $\left(\chi^{2}\right)$ tests were utilized to determine the significance of the association between groups with a $2 \times 2$ contingency table. The results were expressed in terms of odds ratio (OR), 95\% confidence intervals $(95 \% \mathrm{CI})$ and $P$ values. Odds ratios (OR) were calculated according to Woolf's method. When one of the critical entry was zero, Haldane's modification was applied to the Woolf equation using the formula: OR $=[(a+1 / 2) \times(d+1 / 2)] /[(b+1 / 2) \times(c+1 / 2)]$, where $a$, $b, c$, and $d$ represent affected individuals carrying the risk allele, nonaffected individuals carrying the risk allele, affected individuals carrying the nonrisk allele, and nonaffected individuals carrying the nonrisk allele, respectively. A $P \leq 0.05$ was considered to be statistically significant. All statistical analyses were performed using SPSS software (version 17.0.0; SPSS, Chicago, IL, USA). The SNPs were tested for HardyWeinberg equilibrium (HWE) and a cut-off $P$ value of 0.01 was set. Haplotype analysis and LD plots were generated using Haploview 4.2.

\section{Results}

All the samples from $450 \mathrm{HCV}$-infected patients and 600 control subjects were genotyped for the two SNPs in the TLR4 gene. Both SNPs, rs4986790 and rs4986791, were in HardyWeinberg equilibrium (HWE) within the study population and the minor allele frequency (MAF) was 0.08 for both SNPs (Table 1). The 450 patients included 354 chronic HCV carriers (CHC), 87 patients diagnosed with liver cirrhosis (Cirr), and 10 patients who have progressed to HCC. Of note, individuals carrying the minor genotypes, rs4986790-GG and rs4986791-TT, were found to be absent among the 450 $\mathrm{HCV}$-infected patients recruited for the study.

A comparison between the HCV-infected patients with healthy controls revealed that the risk alleles rs4986791-T $\left(\mathrm{OR}=0.298\right.$; 95\% CI. 0.201-0.443, $\chi^{2}$-value of 39.59 and $P<0.0001)$ and rs4986790-G $(\mathrm{OR}=0.404$; 95\% CI. 0.281$0.581, \chi^{2}$-value of 25.25 and $\left.P<0.0001\right)$ were found to be significantly distributed in HCV-infected patients (Table 2). The difference in the distribution of CC genotype of rs4986791 among patients $(\mathrm{CC}=93 \%)$ and controls $(\mathrm{CC}=$ $78 \%$ ) in comparison to the CT genotype (patients: $7 \%$; controls: $22 \%$ ), indicated that the individuals who carry the $\mathrm{C}$ allele recessively could be susceptible to $\mathrm{HCV}$ infection, as the $\mathrm{T}$ allele was found to have a significantly protective role in the dominant model with an OR of 0.274 ; 95\% CI. $0.182-0.412$ and a $P$ value $<0.0001$. A similar significant association was observed in the dominant model with an $\mathrm{OR}=0.382 ; 95 \% \mathrm{CI}$. $0.262-0.557$ and a $P$ value $<0.0001$ for rs4986790 with A as the dominant allele.

Since the development of HCC in HCV patients is as a result of cirrhosis of the liver, internal comparisons among the patient groups were done to determine whether the SNPs have any association with disease progression. However, these analyses revealed no statistical significance when $\mathrm{CHC}$ patients were compared to Cirr patients (Table 3 ) or Cirr/HCC patients (Table 4).

The two SNPs were found to be in a moderate linkage disequilibrium (LD) with $D^{\prime}=0.56, r^{2}=0.307$ and an LOD 
TABLE 3: Genotypic distribution of TLR4 SNPs between chronic HCV patients (CHC) and patients with liver cirrhosis (Cirr).

\begin{tabular}{|c|c|c|c|c|c|c|}
\hline SNPs & $\begin{array}{c}\text { Genotype/allele } \\
\text { distribution }\end{array}$ & $\begin{array}{c}\text { Chronic HCV } \\
\text { patients }\end{array}$ & $\begin{array}{c}\text { Patients with liver } \\
\text { cirrhosis }\end{array}$ & OR (95\% CI.) & $\chi^{2}$ & $P$ value \\
\hline \multirow{7}{*}{ rs4986791 } & $\mathrm{CC}$ & $332(94.0 \%)$ & $77(89.5 \%)$ & 1.0000 (Ref.) & & \\
\hline & CT & $22(6.0 \%)$ & $9(10.5 \%)$ & $1.764(0.781-3.982)$ & 1.91 & 0.167 \\
\hline & $\mathrm{TT}$ & $0(0 \%)$ & $0(0 \%)$ & nan & & \\
\hline & $\mathrm{C}$ & $686(96.9 \%)$ & $163(94.8 \%)$ & 1.0000 (Ref.) & & \\
\hline & $\mathbf{T}$ & $22(3.1 \%)$ & $9(5.2 \%)$ & $1.722(0.778-3.809)$ & 1.84 & 0.175 \\
\hline & $\mathrm{TT}+\mathrm{CT}$ versus $\mathrm{CC}$ & & & $1.764(0.781-3.982)$ & 1.91 & 0.167 \\
\hline & TT versus CT + CC & & & nan & & \\
\hline \multirow{7}{*}{ rs4986790 } & $\mathrm{AA}$ & $323(91.8 \%)$ & $75(86.2 \%)$ & 1.0000 (Ref.) & & \\
\hline & AG & $29(8.2 \%)$ & $12(13.8 \%)$ & $1.782(0.869-3.654)$ & 2.54 & 0.111 \\
\hline & GG & $0(0 \%)$ & $0(0 \%)$ & nan & & \\
\hline & A & $675(95.9 \%)$ & $162(93.1 \%)$ & 1.0000 (Ref.) & & \\
\hline & G & $29(4.1 \%)$ & $12(6.9 \%)$ & $1.724(0.861-3.452)$ & 2.42 & 0.120 \\
\hline & GG versus $A G+A A$ & & & nan & & \\
\hline & $\mathrm{GG}+\mathrm{AG}$ versus $\mathrm{AA}$ & & & $1.782(0.869-3.654)$ & 2.54 & 0.110 \\
\hline
\end{tabular}

Risk allele marked in bold letters.

TABLE 4: Genotypic distribution of TLR4 SNPs in chronic HCV carriers (CHC) compared with both patients with liver cirrhosis (Cirr) and patients with HCC combined.

\begin{tabular}{|c|c|c|c|c|c|c|}
\hline SNPs & $\begin{array}{c}\text { Genotype/allele } \\
\text { distribution }\end{array}$ & $\begin{array}{c}\text { Chronic HCV } \\
\text { patients }\end{array}$ & $\begin{array}{l}\text { Patients with liver } \\
\text { cirrhosis + HCC }\end{array}$ & OR (95\% CI.) & $x^{2}$ & $P$ value \\
\hline \multirow{7}{*}{ rs4986791 } & $\mathrm{CC}$ & $332(94.0 \%)$ & $86(89.6 \%)$ & 1.0000 (Ref.) & & \\
\hline & $\mathrm{CT}$ & $22(6.0 \%)$ & $10(10.4 \%)$ & $1.755(0.801-3.844)$ & 2.02 & 0.155 \\
\hline & $\mathrm{TT}$ & $0(0 \%)$ & $0(0 \%)$ & nan & & \\
\hline & $\mathrm{C}$ & $686(96.9 \%)$ & $182(94.8 \%)$ & 1.0000 (Ref.) & & \\
\hline & $\mathrm{T}$ & $22(3.1 \%)$ & $10(5.2 \%)$ & $1.713(0.797-3.682)$ & 1.94 & 0.163 \\
\hline & $\mathrm{TT}+\mathrm{CT}$ versus $\mathrm{CC}$ & & & $1.755(0.801-3.844)$ & 2.02 & 0.155 \\
\hline & TT versus $\mathrm{CT}+\mathrm{CC}$ & & & nan & & \\
\hline \multirow{7}{*}{ rs4986790 } & AA & $323(91.8 \%)$ & $85(87.6 \%)$ & 1.0000 (Ref.) & & \\
\hline & AG & $29(8.2 \%)$ & $12(12.4 \%)$ & $1.572(0.770-3.211)$ & 1.565 & 0.211 \\
\hline & GG & $0(0 \%)$ & $0(0 \%)$ & nan & & \\
\hline & A & $675(95.9 \%)$ & $182(93.8 \%)$ & 1.0000 (Ref.) & & \\
\hline & G & $29(4.1 \%)$ & $12(6.2 \%)$ & $1.535(0.724-3.203)$ & 1.49 & 0.222 \\
\hline & GG versus $A G+A A$ & & & nan & & \\
\hline & $\mathrm{GG}+\mathrm{AG}$ versus $\mathrm{AA}$ & & & $1.572(0.770-3.211)$ & 1.565 & 0.211 \\
\hline
\end{tabular}

Risk allele marked in bold letters.

score of 50.47. When HCV patients were compared to healthy control group, four haplotypes were found to be significant - AC, GT, GC, and AT. Out of the four, rs4986790 (A)/rs4986791 (C) was found to be the most frequently occurring haplotype with a frequency of 0.888 and $P<0.0001$ (Table 5). More importantly, the AC haplotype was found to be significant when $\mathrm{CHC}$ patients were compared with Cirr patients (frequency $=0.947 ; P=0.031$ ) (Table 6) or with Cirr/HCC patients (frequency 0.947 and $P=0.041$ ) (Table 7).

\section{Discussion}

HCV causes significant health problems worldwide, as infection with the virus could lead to serious liver abnormalities including cirrhosis and HCC [4]. Variables such as old age, high ALT levels, high AFP levels, advanced fibrosis, virus genotype/subgenotype, and nonsustained virological response (non-SVR) are well-established risk factors for the severity of HCV infection, especially for the development of HCC [27-29]. However, host genetic factors have been shown 
TABLE 5: Haplotype association analysis between healthy control subjects and HCV-infected patients.

\begin{tabular}{ccccccc}
\hline \multicolumn{2}{c}{ Haplotype blocks } & Freq. & $\begin{array}{c}\text { HCV patients, healthy } \\
\text { control ratio counts }\end{array}$ & $\begin{array}{c}\text { HCV patients, healthy } \\
\text { control frequencies }\end{array}$ & $\chi^{2}$ & $P$ value \\
\hline rs4986790 & rs4986791 & & & & \\
A & C & 0.888 & $855.1: 48.9,1014.2: 185.8$ & $0.946,0.845$ & 52.75 & $\mathbf{3 . 7 9} \times \mathbf{1 0}^{-\mathbf{1 3}}$ \\
G & T & 0.047 & $25.0: 879.0,73.2: 1126.8$ & $0.028,0.061$ & 12.915 & $\mathbf{0 . 0 0 0 3}$ \\
G & C & 0.033 & $16.3: 887.7,53.8: 1146.2$ & $0.018,0.045$ & 11.557 \\
A & T & 0.032 & $7.7: 896.3,58.8: 1141.2$ & $0.009,0.049$ & $\mathbf{0 . 0 0 0 7}$ \\
\hline
\end{tabular}

TABLE 6: Haplotype association analysis between chronic HCV carriers (CHC) and patients with liver cirrhosis (Cirr).

\begin{tabular}{cccccc}
\hline \multicolumn{2}{c}{ Haplotype blocks } & Freq. & $\begin{array}{c}\text { Liver cirrhosis, } \\
\text { chronic HCV ratio } \\
\text { counts }\end{array}$ & $\begin{array}{c}\text { Liver cirrhosis, } \\
\text { chronic HCV } \\
\text { frequencies }\end{array}$ & $\chi^{2}$ \\
\hline rs4986790 & rs4986791 & & & & \\
A & C & 0.947 & $159.0: 15.0,677.8: 32.2$ & $0.914,0.955$ & 4.652 \\
G & T & 0.029 & $6.6: 167.4,18.9: 691.1$ & $0.038,0.027$ & 0.632 \\
G & C & 0.018 & $5.4: 168.6,10.2: 699.8$ & $0.031,0.014$ & 0.426 \\
\hline
\end{tabular}

TABLE 7: Haplotype association analysis between chronic HCV carriers (CHC) and both patients with liver cirrhosis (Cirr) and patients with HCC combined.

\begin{tabular}{cccccc}
\hline \multicolumn{2}{c}{ Haplotypes block } & Freq. & $\begin{array}{c}\text { Liver cirrhosis + HCC, } \\
\text { chronic HCV ratio } \\
\text { counts }\end{array}$ & $\begin{array}{c}\text { Liver cirrhosis }+ \\
\text { HCC, chronic HCV } \\
\text { frequencies }\end{array}$ & $\chi^{2}$ \\
\hline rs4986790 & rs4986791 & & & & \\
A & $\mathrm{C}$ & 0.947 & $178.0: 16.0,677.8: 32.2$ & $0.917,0.955$ & 4.193 \\
G & $\mathrm{T}$ & 0.028 & $6.6: 187.4,18.9: 691.1$ & $0.034,0.027$ & 0.04 \\
G & $\mathrm{C}$ & 0.017 & $5.4: 188.6,10.2: 699.8$ & $0.028,0.014$ & 0.584 \\
\hline
\end{tabular}

to greatly influence the development of HCV-associated diseases [30]. Several studies have shown that variations in host genes could modulate $\mathrm{HCV}$ infection. For example, polymorphisms in IL28B gene were shown to influence the effectiveness of IFN-based therapy [31] and virus clearance [7]. Also, variations in other genes such as MICA [32], cytokines [33], chemokines [34], and DEPDC5 locus [35] were shown to be associated with disease progression in $\mathrm{HCV}$-infected patients.

Ten TLRs were characterized in humans. TLR1, TLR2, and TLR6 were shown to interact with microbial lipoproteins, glycoproteins, and peptidoglycans. During the initial steps of an infection, these receptors participate in the recognition of such microbial antigens. Genomic DNA or RNA from several pathogens, including viruses, bacteria, and protozoa, is sensed and recognized by TLR9, which is also capable of recognizing modified forms of DNA such as unmethylated CpG islands. Single stranded RNA (ssRNA) and double stranded RNA (dsRNA) from viruses, such as West Nile virus (WNV), respiratory syncytial virus (RSV), HIV, and influenza virus, were found to be recognized by TLR3, TLR7, and TLR8. Although the exact function of TLR10 has not been fully elucidated, it is thought that it recognizes profilin-like molecules $[36,37]$. TLR4 was the first TLR identified and it is a transmembrane receptor that has a critical role in innate immune system against infectious organisms [38]. TLR4 is expressed in several types of liver cells including hepatic stellate cell (HSC), hepatocytes, Kupffer cells, and biliary cells [21]. The mechanism of activation of TLR4 pathway is quite complex. It requires several auxiliary proteins (LBP and CD14) as well as a coreceptor called MD-2 [37]. MD2 is a soluble protein with a large hydrophobic pocket and it was implicated in representing LPS to bind to TLR4 [39]. The MD-2 and TLR4 make a heterodimeric structure that interacts with LPS and results in the activation of the TLR4 signaling cascade $[39,40]$. It was found that this heterodimer recruits two independent intracellular adaptor proteins (MyD88/TIRAP and TRIF/TRAM) which are involved in activation of two parallel signaling pathways that trigger the transcription of both proinflammatory cytokines and type I Interferon [41]. Of importance, TLR4 and MyD88deficient mice developed significantly less liver tumors after feeding with the carcinogenic chemical, diethylnitrosamine. This observation suggests that TLR4-MyD88 signaling pathway plays a role in the development of liver tumor [42]. Although the main ligand for TLR4 is the bacteria endotoxin 
lipopolysaccharides (LPS) [12], it was also found that several $\mathrm{HCV}$ proteins, such as nonstructural protein 5A (NS5A), core, and NS3, stimulate TLR4 pathway [21].

Due to the importance of TLR4 in innate immunity, several studies have examined the role of TLR4 polymorphism in human diseases. Genetic variations in TLR4 gene have been linked to susceptibility to several infectious agents such as bacterial infection [43-45], viral infection [46, 47], malaria [48-50], hepatic fibrosis [25], and HCV-associated HCC [51]. Also, such variations have been reported to be associated with a wide variety of noninfectious diseases including diabetic neuropathy [52], atherosclerosis [53], rheumatoid arthritis [54], and premature birth [55]. TLR4 induction, signaling, and activation in numerous cancers such as breast cancer, colon cancer, ovarian, and prostate cancer were also identified [56]. Moreover, the induction of TLR4 was implicated as the molecular mechanism mediating liver damage and tumor formation in alcohol abused patients [57].

In this study, we examined the role of two nonsynonymous SNPs, rs4986790 (D299G) and rs4986791 (T399I), located at the third exon of the TLR4 gene on HCV infection. This was based on the observation that missense variations at these locations were implicated on the activity of TLR4 in inflammatory and fibrogenic signaling pathways [25]. Our findings showed that variations at these locations were found to be significantly associated with chronic HCV infection among Saudi nationals but not with HCV-induced liver abnormalities including cirrhosis or HCC. The minor allele carriers of both the SNPs (rs4986791-T and rs4986790-G) were comparatively lower in number among patients than in the control group, suggesting that variations at both SNPs could have a protective effect against HCV infection. Although, these results suggest that both genotypes could play a role in HCV infection, the clinical significance of this finding needs more investigation. Therefore, the probable protective effect of the two SNPs on HCV infection might be biologically possible from these facts but in order to confirm this, the present study must be replicated with more study subjects to rule out the possibility of population bias or the differences in ethnic background. Studies conducted in Spanish [51, 58] and Japanese [59] populations have reported no such significant associations, while in a study conducted among Caucasians, rs4986791-C was found to be associated with hepatic fibrosis progression, which was consistent with the present study [23]. In addition, the two SNPs were found to have a protective role among chronic hepatitis $\mathrm{C}$ infected Caucasians with liver fibrosis [24].

Interestingly, a study conducted by Tamura et al. [60] reported that HCV NS5A protein inhibited LPS-induced apoptosis of hepatocytes by downregulating the expression of TLR4 and thus might play a role in the pathogenesis of $\mathrm{HCV}$ infection [60]. In another study conducted by Ohto et al. [61], the two TLR4 SNPs were found to modulate the surface properties of TLR4 and hence might affect LPS binding to the TLR4-MD2 complex [61]. It has also been suggested that variation at these SNPs causes impairment of TLR4/MD-2 responses as a result of interfering with ligand-dependent dimerization [62]. The two SNPs have been found to be associated with hyporesponsiveness to LPS
[63]. In a study conducted by Guo et al. [25], it was reported that the two TLR4 SNPs reduced the growth of murine hepatic stellate cells (mHSCs) and conferred an increased rate of spontaneous apoptosis in mHSCs [25]. On the contrary, it was also reported that the variation at amino acid 299 (D299G) causes inefficient recruitment of MyD88 and TRIF to TLR4, without disrupting the TLR4 expression, TLR4MD2 interaction, or LPS binding and resulting in the impairment of TLR4 signaling pathway and thus playing a role in HCV pathogenesis [64].

According to NCBI HapMap database, the frequency of both SNPs investigated in this study has been documented in different ethnic populations. For rs4986790, the frequency was as follows: European $(A=0.967$ and $G=0.033)$, Chinese Han $(A=1.000$ and $G=0.000)$, Japanese $(A=1.000$ and $\mathrm{G}=0.000)$, Gujarati Indians in Houston $(A=0.902, \mathrm{G}=$ 0.098), and African Yoruba $(A=0.967$ and $G=0.033)$ populations. The allele frequencies observed among the Gujarati Indians were comparable to those observed among the Saudi Arabian population $(A=0.919$ and $G=0.082)$. Similarly, the allele frequency for SNP rs4986791 is reported as follows: Europeans: $(\mathrm{C}=0.955, \mathrm{~T}=0.045)$, Chinese Han: $(\mathrm{C}=0.988, \mathrm{~T}=0.012)$, Japanese: $(\mathrm{C}=1.000, \mathrm{~T}=0.000)$, Gujarati Indians $(\mathrm{C}=0.897, \mathrm{~T}=0.103)$, and African Yoruba $(\mathrm{C}=1.000, \mathrm{~T}=0.000)$. The allele frequencies observed among the Saudi Arabian population $(\mathrm{A}=0.922$ and $\mathrm{G}=0.078)$ was comparable to the Gujarati Indians and the European population.

Haplotype analysis revealed four significant haplotypes, AC, GT, GC, and AT between patient and control groups. However, the risk AC (rs4986790, rs4986791, resp.) haplotype was found to be more frequently occurring within the study population and comparatively more among the HCVinfected group than in controls, which accentuates the results of our study that the rs4986790-G and rs4986791-T alleles could have a protective role in $\mathrm{HCV}$ infection.

\section{Conclusion}

Both the TLR4 missense SNPs used in this study, rs4986790 and rs4986791 were found to be associated significantly with HCV-infected patients in the Saudi Arabian population. However, no significant association was found with advanced $\mathrm{HCV}$-associated diseases such as cirrhosis and HCC.

\section{Conflict of Interests}

The authors declare that there is no conflict of interests regarding the publication of this paper.

\section{Acknowledgments}

This study was supported in part by a grant from King Abdulaziz City for Science and Technology, Project no. ARP27-18. This study was approved by Research Advisory Council (RAC) of King Faisal Specialist Hospital and Research Centre, RAC no. 2060040. The support of the Research Center administration at King Faisal Specialist Hospital and 
Research Center was highly appreciated. The authors are grateful to Hanan Shaarawi and Maureene Delos Reyes for secretarial and logistic assistance.

\section{References}

[1] E. J. Gane, "The natural history of recurrent hepatitis $C$ and what influences this," Liver Transplantation, vol. 14, supplement 2, pp. S36-S44, 2008.

[2] Y. V. Svitkin, A. Pause, M. Lopez-Lastra, S. Perreault, and N. Sonenberg, "Complete translation of the hepatitis $\mathrm{C}$ virus genome in vitro: membranes play a critical role in the maturation of all virus proteins except for NS3," Journal of Virology, vol. 79, no. 11, pp. 6868-6881, 2005.

[3] P. Simmonds, J. Bukh, C. Combet et al., "Consensus proposals for a unified system of nomenclature of hepatitis C virus genotypes," Hepatology, vol. 42, no. 4, pp. 962-973, 2005.

[4] L. B. Seeff, "Natural history of chronic hepatitis C," Hepatology, vol. 36, supplement 1, no. 5, pp. S35-S46, 2002.

[5] M. Thursz, L. Yee, and S. Khakoo, "Understanding the host genetics of chronic hepatitis B and C," Seminars in Liver Disease, vol. 31, no. 2, pp. 115-127, 2011.

[6] Y. Tanaka, N. Nishida, M. Sugiyama et al., "Genome-wide association of IL28B with response to pegylated interferon- $\alpha$ and ribavirin therapy for chronic hepatitis C," Nature Genetics, vol. 41, no. 10, pp. 1105-1109, 2009.

[7] D. L. Thomas, C. L. Thio, M. P. Martin et al., "Genetic variation in IL28B and spontaneous clearance of hepatitis C virus," Nature, vol. 461, no. 7265, pp. 798-801, 2009.

[8] H. Abe, H. Ochi, T. Maekawa et al., "Common variation of IL28 affects gamma-GTP levels and inflammation of the liver in chronically infected hepatitis C virus patients," Journal of Hepatology, vol. 53, no. 3, pp. 439-443, 2010.

[9] D. Eurich, S. Boas-Knoop, M. Bahra et al., "Role of IL28B polymorphism in the development of hepatitis $C$ virus-induced hepatocellular carcinoma, graft fibrosis, and posttransplant antiviral therapy," Transplantation, vol. 93, no. 6, pp. 644-649, 2012.

[10] B. P. Doehle and M. Gale Jr., "evasion strategies of HCV and HIV: common themes for chronic viral infection," in Nucleic Acid Sensors and Antiviral Immunity, S. Sambhara and T. Fujita, Eds., Landes Bioscience, 2012.

[11] E. Thomas, V. D. Gonzalez, Q. Li et al., "HCV infection induces a unique hepatic innate immune response associated with robust production of type III interferons," Gastroenterology, vol. 142, no. 4, pp. 978-988, 2012.

[12] B. Ferwerda, M. B. B. McCall, K. Verheijen et al., "Functional consequences of Toll-like receptor 4 polymorphisms," Molecular Medicine, vol. 14, no. 5-6, pp. 346-352, 2008.

[13] U. Düesberg, A. von Dem Bussche, C. J. Kirschning, K. Miyake, T. Sauerbruch, and U. Spengler, "Cell activation by synthetic lipopeptides of the hepatitis $\mathrm{C}$ virus ( $\mathrm{HCV}$ )-core protein is mediated by toll like receptors (TLRs) 2 and 4," Immunology Letters, vol. 84, no. 2, pp. 89-95, 2002.

[14] S. Chang, A. Dolganiuc, and G. Szabo, "Toll-like receptors 1 and 6 are involved in TLR2-mediated macrophage activation by hepatitis C virus core and NS3 proteins," Journal of Leukocyte Biology, vol. 82, no. 3, pp. 479-487, 2007.
[15] A. Dolganiuc, S. Oak, K. Kodys et al., "Hepatitis C core and nonstructural 3 proteins trigger toll-like receptor 2-mediated pathways and inflammatory activation," Gastroenterology, vol. 127, no. 5, pp. 1513-1524, 2004.

[16] M. Ait-Goughoulte, A. Banerjee, K. Meyer, B. Mazumdar, K. Saito, and R. B. Ray, "Hepatitis C virus core protein interacts with fibrinogen- $\beta$ and attenuates cytokine stimulated acutephase response," Hepatology, vol. 51, no. 5, pp. 1505-1513, 2010.

[17] N. Arnaud, S. Dabo, D. Akazawa et al., "Hepatitis C virus reveals a novel early control in acute immune response," PLoS Pathogens, vol. 7, no. 10, Article ID e1002289, 2011.

[18] S. J. Polyak, K. S. A. Khabar, D. M. Paschal et al., "Hepatitis C virus nonstructural $5 \mathrm{~A}$ protein induces interleukin-8, leading to partial inhibition of the interferon-induced antiviral response," Journal of Virology, vol. 75, no. 13, pp. 6095-6106, 2001.

[19] E. A. Kurt-Jones, L. Popova, L. Kwinn et al., "Pattern recognition receptors TLR4 and CD14 mediate response to respiratory syncytial virus," Nature Immunology, vol. 1, no. 5, pp. 398-401, 2000.

[20] J. C. Rassa, J. L. Meyers, Y. Zhang, R. Kudaravalli, and S. R. Ross, "Murine retroviruses activate B cells via interaction with Tolllike receptor 4," Proceedings of the National Academy of Sciences of the United States of America, vol. 99, no. 4, pp. 2281-2286, 2002.

[21] J. Howell, P. Angus, P. Gow, and K. Visvanathan, “Toll-like receptors in hepatitis $\mathrm{C}$ infection: implications for pathogenesis and treatment," Journal of Gastroenterology and Hepatology, vol. 28, no. 5, pp. 766-776, 2013.

[22] K. Machida, K. T. H. Cheng, V. M. Sung, A. M. Levine, S. Foung, and M. M. C. Lai, "Hepatitis C virus induces toll-like receptor 4 expression, leading to enhanced production of beta interferon and interleukin-6," Journal of Virology, vol. 80, no. 2, pp. 866874, 2006.

[23] H. Huang, M. L. Shiffman, S. Friedman et al., "A 7 gene signature identifies the risk of developing cirrhosis in patients with chronic hepatitis C," Hepatology, vol. 46, no. 2, pp. 297-306, 2007.

[24] Y. Li, M. Chang, O. Abar et al., "Multiple variants in toll-like receptor 4 gene modulate risk of liver fibrosis in Caucasians with chronic hepatitis C infection," Journal of Hepatology, vol. 51, no. 4, pp. 750-757, 2009.

[25] J. Guo, J. Loke, F. Zheng et al., "Functional linkage of cirrhosispredictive single nucleotide polymorphisms of Toll-like receptor 4 to hepatic stellate cell responses," Hepatology, vol. 49, no. 3, pp. 960-968, 2009.

[26] A. A. Abdo, H. A. A. Karim, T. Al Fuhaid et al., "Saudi gastroenterology association guidelines for the diagnosis and management of hepatocellular carcinoma: summary of recommendations," Annals of Saudi Medicine, vol. 26, no. 4, pp. 261265, 2006.

[27] R. Bataller, K. E. North, and D. A. Brenner, "Genetic polymorphisms and the progression of liver fibrosis: a critical appraisal," Hepatology, vol. 37, no. 3, pp. 493-503, 2003.

[28] K. C. Chang, Y. Y. Wu, C. H. Hung et al., "Clinical-guide risk prediction of hepatocellular carcinoma development in chronic hepatitis C patients after interferon-based therapy," The British Journal of Cancer, vol. 109, no. 9, pp. 2481-2488, 2013.

[29] A. Mallat, C. Hezode, and S. Lotersztajn, "Environmental factors as disease accelerators during chronic hepatitis C," Journal of Hepatology, vol. 48, no. 4, pp. 657-665, 2008. 
[30] S. J. Chapman and A. V. S. Hill, "Human genetic susceptibility to infectious disease," Nature Reviews Genetics, vol. 13, no. 3, pp. 175-188, 2012.

[31] P. J. Clark and A. J. Thompson, "Host genomics and HCV treatment response," Journal of Gastroenterology and Hepatology, vol. 27, no. 2, pp. 212-222, 2012.

[32] V. Kumar, N. Kato, Y. Urabe et al., "Genome-wide association study identifies a susceptibility locus for HCV-induced hepatocellular carcinoma," Nature Genetics, vol. 43, no. 5, pp. 455-458, 2011.

[33] Y. Yang, C. Luo, R. Feng, and S. Bi, "The TNF- $\alpha$, IL-1B and IL-10 polymorphisms and risk for hepatocellular carcinoma: a metaanalysis," Journal of Cancer Research and Clinical Oncology, vol. 137, no. 6, pp. 947-952, 2011.

[34] K. Promrat, D. H. McDermott, C. M. Gonzalez et al., "Associations of chemokine system polymorphisms with clinical outcomes and treatment responses of chronic hepatitis C," Gastroenterology, vol. 124, no. 2, pp. 352-360, 2003.

[35] D. Miki, H. Ochi, C. N. Hayes et al., "Variation in the DEPDC5 locus is associated with progression to hepatocellular carcinoma in chronic hepatitis C virus carriers," Nature Genetics, vol. 43, no. 8, pp. 797-800, 2011.

[36] S. Akira and K. Takeda, "Toll-like receptor signalling," Nature Reviews Immunology, vol. 4, no. 7, pp. 499-511, 2004.

[37] L. A. J. O'Neill, C. E. Bryant, and S. L. Doyle, “Therapeutic targeting of toll-like receptors for infectious and inflammatory diseases and cancer," Pharmacological Reviews, vol. 61, no. 2, pp. 177-197, 2009.

[38] B. Beutler, "Innate immune responses to microbial poisons: discovery and function of the Toll-like receptors," Annual Review of Pharmacology and Toxicology, vol. 43, pp. 609-628, 2003.

[39] B. S. Park, D. H. Song, H. M. Kim, B. Choi, H. Lee, and J. Lee, "The structural basis of lipopolysaccharide recognition by the TLR4-MD-2 complex," Nature, vol. 458, no. 7242, pp. 1191-1195, 2009.

[40] N. Resman, J. Vašl, A. Oblak et al., "Essential roles of hydrophobic residues in both MD-2 and toll-like receptor 4 in activation by endotoxin," The Journal of Biological Chemistry, vol. 284, no. 22, pp. 15052-15060, 2009.

[41] T. Kawai and S. Akira, "TLR signaling," Cell Death and Differentiation, vol. 13, no. 5, pp. 816-825, 2006.

[42] A. G. Testro and K. Visvanathan, "Toll-like receptors and their role in gastrointestinal disease," Journal of Gastroenterology and Hepatology, vol. 24, no. 6, pp. 943-954, 2009.

[43] J. Faber, C. U. Meyer, C. Gemmer et al., "Human toll-like receptor 4 mutations are associated with susceptibility to invasive meningococcal disease in infancy," Pediatric Infectious Disease Journal, vol. 25, no. 1, pp. 80-81, 2006.

[44] B. D. Taylor, T. Darville, R. E. Ferrell, C. M. Kammerer, R. B. Ness, and C. L. Haggerty, "Variants in toll-like receptor 1 and 4 genes are associated with chlamydia trachomatis among women with pelvic inflammatory disease," Journal of Infectious Diseases, vol. 205, no. 4, pp. 603-609, 2012.

[45] K. Tietze, A. Dalpke, S. Morath, R. Mutters, K. Heeg, and C. Nonnenmacher, "Differences in innate immune responses upon stimulation with gram-positive and gram-negative bacteria," Journal of Periodontal Research, vol. 41, no. 5, pp. 447-454, 2006.
[46] A. A. Awomoyi, P. Rallabhandi, T. I. Pollin et al., "Association of TLR4 polymorphisms with symptomatic respiratory syncytial virus infection in high-risk infants and young children," Journal of Immunology, vol. 179, no. 5, pp. 3171-3177, 2007.

[47] J. F. Wu, C. Chen, Y. Ni et al., "Toll-like receptor and hepatitis $B$ virus clearance in chronic infected patients: a long-term prospective cohort study in Taiwan," Journal of Infectious Diseases, vol. 206, no. 5, pp. 662-668, 2012.

[48] P. Bali, S. Pradhan, D. Sharma, and T. Adak, "Toll like receptor 2 and 4 polymorphisms in malaria endemic populations of India," Human Immunology, vol. 74, no. 2, pp. 223-229, 2013.

[49] M. Basu, A. K. Maji, A. Chakraborty et al., "Genetic association of Toll-like-receptor 4 and tumor necrosis factor- $\alpha$ polymorphisms with Plasmodium falciparum blood infection levels," Infection, Genetics and Evolution, vol. 10, no. 5, pp. 686-696, 2010.

[50] F. P. Mockenhaupt, J. P. Cramer, L. Hamann et al., “Toll-like receptor (TLR) polymorphisms in African children: Common TLR- 4 variants predispose to severe malaria," Proceedings of the National Academy of Sciences of the United States of America, vol. 103, no. 1, pp. 177-182, 2006.

[51] J. A. Agúndez, E. García-Martín, M. J. Devesa et al., "Polymorphism of the TLR4 gene reduces the risk of hepatitis C virusinduced hepatocellular carcinoma," Oncology, vol. 82, no. 1, pp. 35-40, 2012.

[52] G. Rudofsky Jr., P. Reismann, S. Witte et al., “Asp299Gly and Thr399Ile genotypes of the TLR4 gene are associated with a reduced prevalence of diabetic neuropathy in patients with type 2 diabetes," Diabetes Care, vol. 27, no. 1, pp. 179-183, 2004.

[53] S. Kiechl, E. Lorenz, M. Reindl et al., "Toll-like receptor 4 polymorphisms and atherogenesis," The New England Journal of Medicine, vol. 347, no. 3, pp. 185-192, 2002.

[54] T. R. D. J. Radstake, B. Franke, S. Hanssen et al., “The Tolllike receptor 4 Asp299Gly functional variant is associated with decreased rheumatoid arthritis disease susceptibility but does not influence disease severity and/or outcome," Arthritis and Rheumatism, vol. 50, no. 3, pp. 999-1001, 2004.

[55] K. S. Crider, N. Whitehead, and R. M. Buus, "Genetic variation associated with preterm birth: a HuGE review," Genetics in Medicine, vol. 7, no. 9, pp. 593-604, 2005.

[56] A. Oblak and R. Jerala, "Toll-like receptor 4 activation in cancer progression and therapy," Clinical and Developmental Immunology, vol. 2011, Article ID 609579, 12 pages, 2011.

[57] K. Machida, H. Tsukamoto, H. Mkrtchyan et al., "Toll-like receptor 4 mediates synergism between alcohol and $\mathrm{HCV}$ in hepatic oncogenesis involving stem cell marker Nanog," Proceedings of the National Academy of Sciences of the United States of America, vol. 106, no. 5, pp. 1548-1553, 2009.

[58] M. J. Citores, I. Baños, A. Noblejas, S. Rosado, R. Castejon, and V. Cuervas-Mons, "Toll-like receptor 3 L412F polymorphism may protect against acute graft rejection in adult patients undergoing liver transplantation for hepatitis C-related cirrhosis," Transplantation Proceedings, vol. 43, no. 6, pp. 2224-2226, 2011.

[59] M. Nakamura, T. Kanda, S. Nakamoto et al., "No correlation between PNPLA3 rs738409 genotype and fatty liver and hepatic cirrhosis in Japanese patients with HCV," PLoS ONE, vol. 8, no. 12, Article ID e81312, 2013.

[60] R. Tamura, T. Kanda, F. Imazeki et al., "Hepatitis C virus nonstructural $5 \mathrm{~A}$ protein inhibits lipopolysaccharide-mediated 
apoptosis of hepatocytes by decreasing expression of toll-like receptor 4," Journal of Infectious Diseases, vol. 204, no. 5, pp. 793-801, 2011.

[61] U. Ohto, N. Yamakawa, S. Akashi-Takamura, K. Miyake, and T. Shimizu, "Structural analyses of human toll-like receptor 4 polymorphisms D299G and T399I," The Journal of Biological Chemistry, vol. 287, no. 48, pp. 40611-40617, 2012.

[62] N. Yamakawa, U. Ohto, S. Akashi-Takamura et al., "Human TLR4 polymorphism D299G/T399I alters TLR4/MD-2 conformation and response to a weak ligand monophosphoryl lipid A," International Immunology, vol. 25, no. 1, pp. 45-52, 2013.

[63] N. C. Arbour, E. Lorenz, B. C. Schutte et al., "TLR4 mutations are associated with endotoxin hyporesponsiveness in humans," Nature Genetics, vol. 25, no. 2, pp. 187-191, 2000.

[64] L. Figueroa, Y. Xiong, C. Song, W. Piao, S. N. Vogel, and A. E. Medvedev, "The Asp 299Gly polymorphism alters TLR4 signaling by interfering with recruitment of MyD88 and TRIF," Journal of Immunology, vol. 188, no. 9, pp. 4506-4515, 2012. 

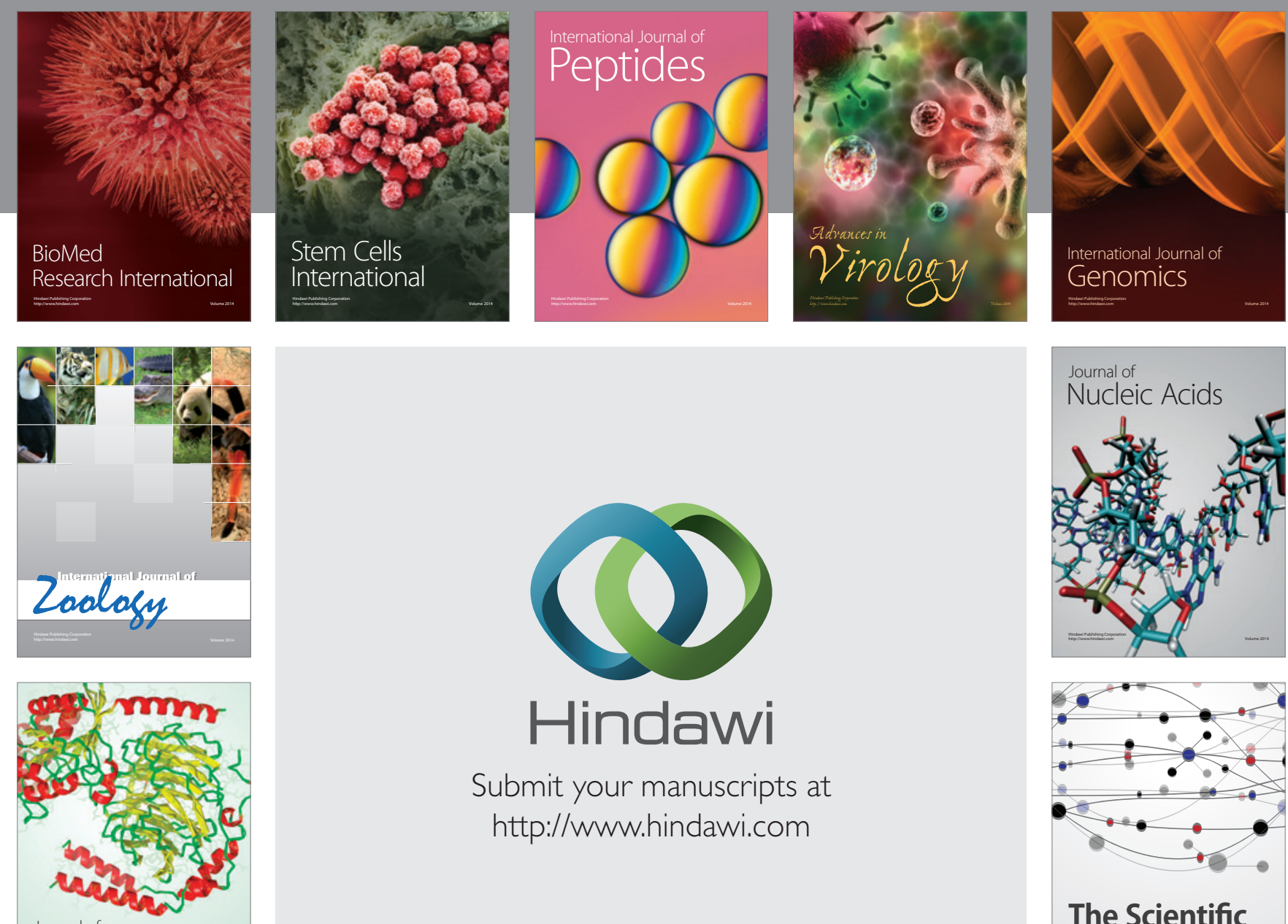

Submit your manuscripts at

http://www.hindawi.com

Journal of
Signal Transduction
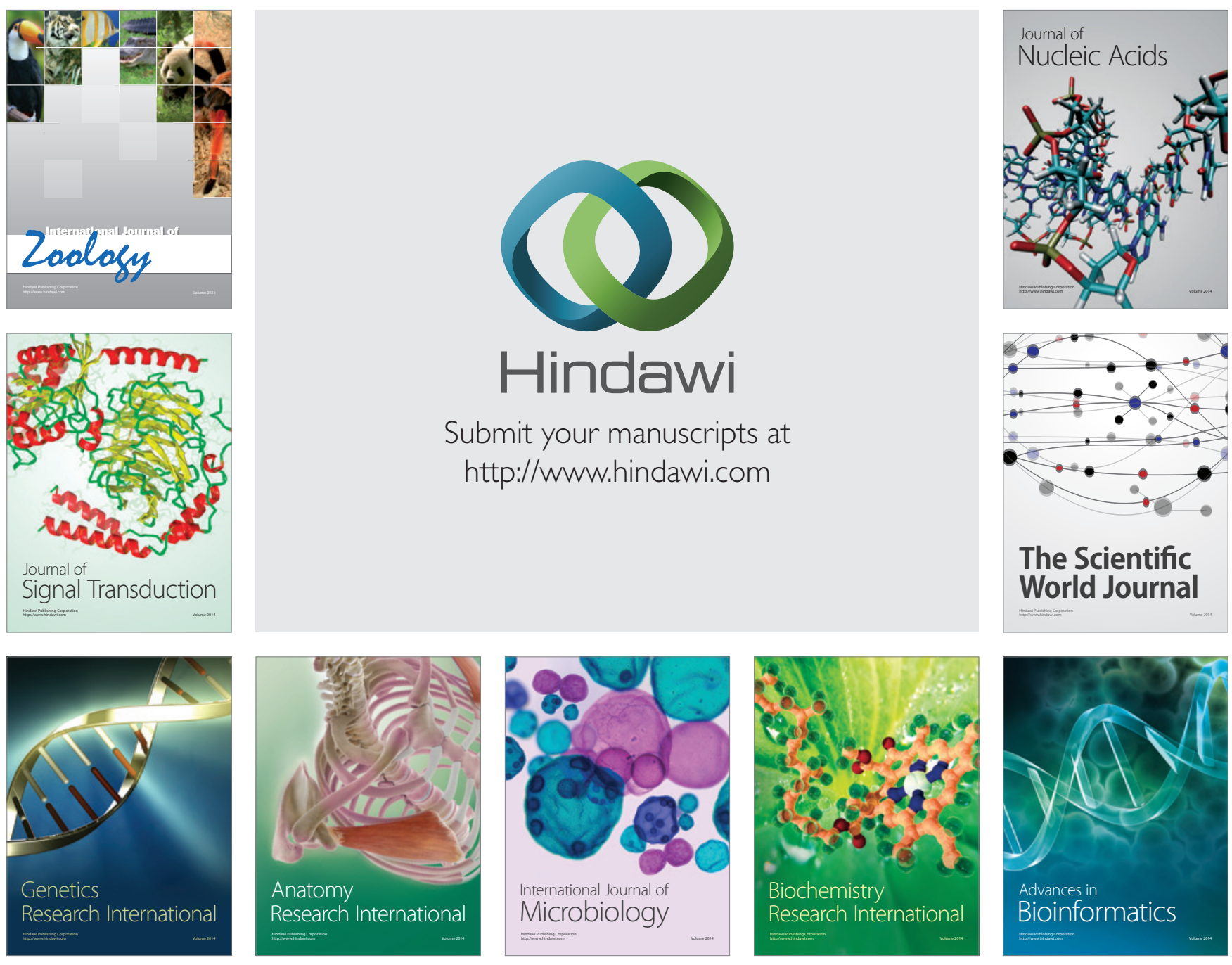

The Scientific World Journal
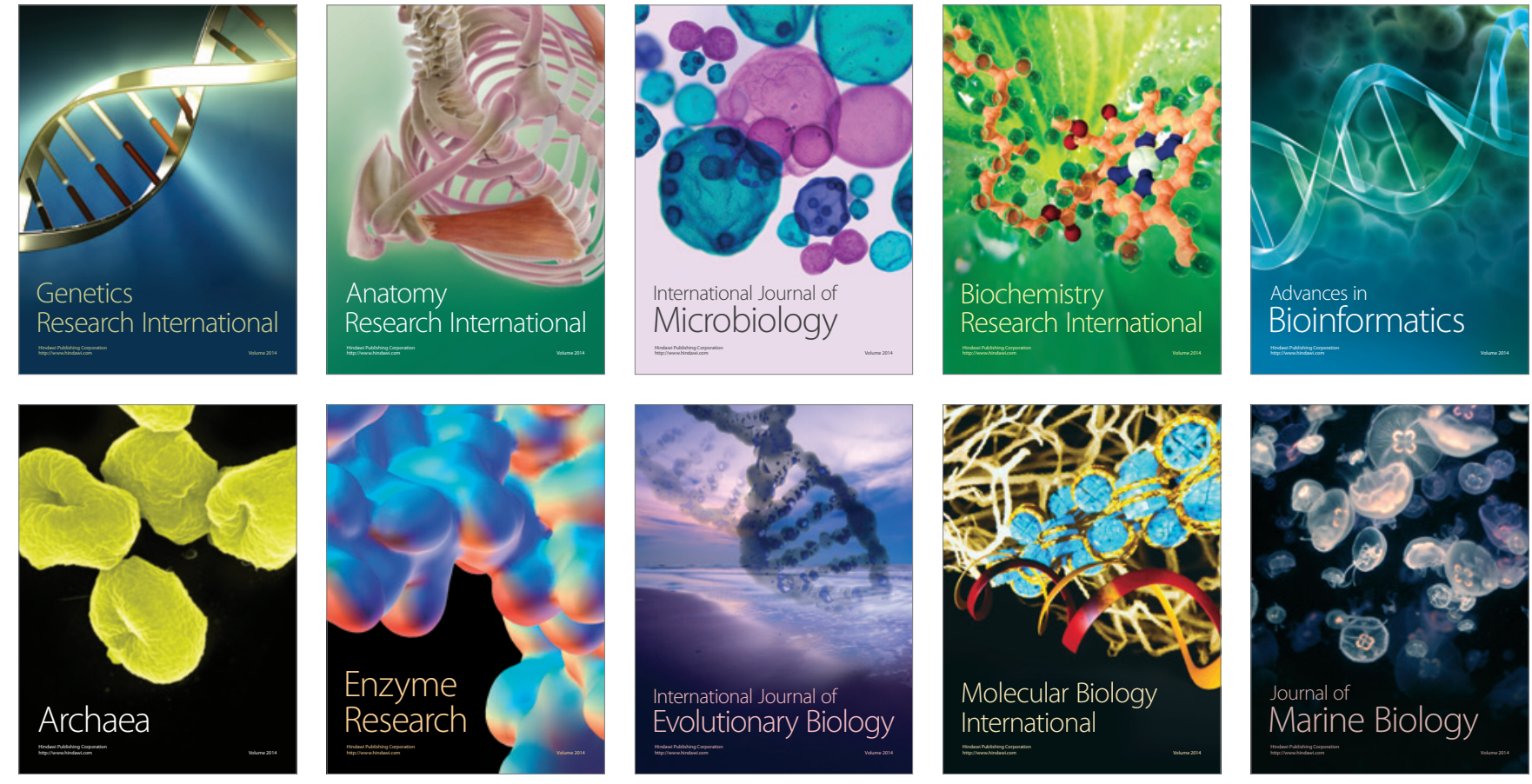